\title{
Toward a model of effective monitoring of IT application development and maintenance suppliers in multisourced environments
}

\author{
Thomas Ph. Herz * Florian Hamel, Falk Uebernickel, Walter Brenner \\ Institute of Information Management, University of St. Gallen (HSG), Mueller-Friedberg-Strasse 8, 9000 St. Gallen, Switzerland
}

\section{A R T I C L E I N F O}

\section{Article history:}

Received 4 August 2011

Received in revised form 28 November 2012 Accepted 11 December 2012

\section{Keywords:}

IT outsourcing

Multisourcing

Performance measurement

KPIs

IT ADM

Case study

\begin{abstract}
A B S T R A C T
Many international corporations are now adopting multisourcing approaches to information technology (IT). Multisourcing is described as the disciplined provision and blending of services from multiple suppliers both outside the company and within the company. This approach to meeting business goals is primarily concerned with the relationship between the client organization and the multiple suppliers. To date, aspects relating to performance measurement and governance have scarcely been covered in the literature, and established IT frameworks such as control objectives for information and related technology (COBIT) provide imprecise approaches for monitoring suppliers. In this study, we intend to sharpen the existing understanding of how corporations manage and monitor suppliers in a multisourced environment and of why specific key performance indicators (KPIs) are utilized. We provide insights using a real-life example of the monitoring of IT application development and maintenance (IT ADM) suppliers and suggest monitoring dimensions based on a cross-case analysis. Based on inter-rater reliability, we further derive a minimum set of corresponding IT ADM KPIs. This study is expected to help corporations facing similar challenges by providing a set of essential KPIs to monitor IT ADM suppliers.
\end{abstract}

(c) 2012 Elsevier Inc. All rights reserved.

\footnotetext{
* Corresponding author. Tel.: +41712242934.

E-mail addresses: thomas.herz@unisg.ch (T. Herz), florian.hamel@unisg.ch (F. Hamel), falk.uebernickel@unisg.ch (F. Uebernickel), walter.brenner@unisg.ch (W. Brenner).
} 


\section{Introduction}

Market researcher International Data Corporation estimated that the global information technology (IT) outsourcing market was worth USD 114.6 billion in 2009, and the market is expected to reach USD 131.3 billion in 2013 (Tapper, 2009). The use of a single-sourcing approach in IT mega-deals valued at more than USD one billion has become less frequent in recent years; instead, companies have moved toward a more selective IT outsourcing approach through the use of multisourcing. In this context, the sourcing advisory firm Technology Partners International found that, while mega-deals have decreased in both size and prevalence, the number of IT outsourcing deals being signed has increased (Huber, 2008; Mayo et al., 2010).

Gartner describes multisourcing as blending the services of multiple suppliers, including suppliers inside and outside of the company, in the pursuit of business goals (Cohen and Young, 2006). Multisourcing is mainly concerned with the relationship between the client organization and the suppliers (Levina and Su, 2008). In addition to Gartner, other market research companies such as Forrester Research have also contributed to practitioner-related literature on multisourcing (see inter alia Davis (2010)). Further, scientific literature describes multisourcing as a "long-term dominant trend in global sourcing" (Oshri et al., 2011, p.130). While practitioner and scholarly research have identified multisourcing as an important emerging strategy in today's IT outsourcing endeavors (Cohen and Young, 2006; Levina and Su, 2008; Janischowsky and Schonenbach, 2009; Oshri et al., 2009, 2011; Bapna et al., 2010; Davis, 2010; Su and Levina, 2011), there has been little scholarly examination of its importance.

From an information systems (IS) research perspective (Dibbern et al., 2004), companies are confronted with 5 major issues concerning IT outsourcing. These issues include (1) why to outsource; (2) what to outsource; (3) which decision-making process to use; (4) how to implement the sourcing decision; and (5) what the outcome of the sourcing decision will be. While the first 3 questions have been thoroughly addressed, the issues regarding implementation and outcomes require further research. Despite the relevance of performance measurement and governance-related aspects of IT outsourcing decisions, these issues have scarcely been covered (Clark et al., 1995; Klepper, 1995; McFarlan and Nolan, 1995; Willcocks and Choi, 1995; Davis, 1996; Dibbern et al., 2004; Gottschalk and Solli-Sæther, 2005; Busi and Mclvor, 2008; Weimer and Seuring, 2009). The majority of IT outsourcing studies address dyadic relationships (see inter alia Willcocks and Lacity (1999)) or investigate performance measurement approaches that are focused solely on internal IT departments (see inter alia Van Grembergen et al. (2004) regarding the IT balanced scorecard (IT BSC)). Very few experience-based studies investigate how corporations manage and monitor suppliers in a multisourced environment. Moreover, the literature suggests that established IT frameworks such as the control objectives for information and related technology, ${ }^{1}$ the Val IT framework, ${ }^{2}$ the information technology infrastructure library ${ }^{3}$ and the capability maturity model integration for development ${ }^{4}$ or effort estimation methods such as the constructive cost model (COCOMO) and function point analysis (FPA) (Albrecht, 1979; Boehm, 1981) provide numerous key performance indicators (KPIs) that are suitable for monitoring suppliers. However, these KPIs are limited because they focus on only one aspect, such as effort estimation (see, for example, COCOMO), or because the number of monitoring KPIs is far too extensive and unspecified (see, for example, COBIT) to implement when managing and monitoring suppliers. In addition, no standard minimum set of KPIs is available for straightforward adoption by practitioners.

\footnotetext{
${ }^{1}$ Control objectives for information and related technology 4.1 (СOBIT 4.1) is a generally accepted internal control framework for IT that is maintained by the IT Governance Institute (ITGI).

2 The Val IT framework 2.0 (VAL IT 2.0) supports the optimization of the realization of value of IT investments and is also maintained by the ITGI. According to the ITGI (2008, p.6), "COBIT sets good practices for the means of contributing to the process of value creation (and) Val IT sets good practices for the ends by providing enterprises with the structure they require to measure, monitor and optimize the realization of business value from investment in IT."

${ }^{3}$ The information technology infrastructure library version 3 (ITIL v3) provides best practices for IT service management and supports the continuous measurement and improvement of the quality of IT services. The ITIL has become the most widely accepted approach in this regard and is maintained by the Cabinet Office (until 2010 by the Office of Government Commerce).

${ }^{4}$ Capability maturity model integration for development version 1.3 (CMMI-DEV v1.3) is a reference model that provides best practices and is frequently applied in a software development and service context. The CMMI models are maintained by the Software Engineering Institute at Carnegie Mellon University.
} 
Accounting information systems (AIS) research "examines interrelated concepts and phenomena which lie at the interface between information technology and accounting" (Nicolaou, 2011, p.81). According to Smith et al. (2005), management accounting plays an important role in managing outsourcing relationships and measuring the outcomes of such engagements. AIS scholars investigate, for example, the impact of outsourcing on IT spending (Kobelsky and Robinson, 2010) or on the firm value (Beasley et al., 2009). Further, Blaskovich and Mintchik (2011) emphasize the opportunities for AIS scholars to investigate the implications of IT outsourcing on AIS, and Caglio and Ditillo (2008) review and discuss the literature on management control in inter-firm relationships. Moreover, Langfield-Smith and Smith (2003) investigate management control systems and trust in outsourcing relationships and argue that appropriate governance structures (such as control systems) support the success of IT outsourcing; however, further research is needed. From a management literature perspective, this finding is in line with McFarlan and Nolan's (1995) study, which claims that ongoing management is the single most important aspect to ensure success in outsourcing. According to McFarlan and Nolan's (1995) study, performance measurement is one critical area in this regard.

In this research study, we intend to bridge the research on IT outsourcing and AIS, thereby sharpening the current understanding of how corporations manage and monitor suppliers in a context of multisourcing. Therefore, we have defined the following overarching research question: How do large corporations monitor suppliers in a multisourced environment?

Grover et al. (1996) differentiate 5 IS functions in IT outsourcing - IT application development and maintenance (IT ADM), system operations, telecommunications, end-user support and system planning and management. To investigate how large corporations monitor suppliers in a multisourcing context, we limited our research to one specific category of IS functions, namely IT ADM. This decision is justified because this IS function is mainly project-driven, in contrast to infrastructure operations (Beulen et al., 2005), and therefore possesses different characteristics (see inter alia Beulen et al. (2005)).

In this regard, the overarching research question can be further divided into the following 3 subresearch questions:

- [RQ 1] Which monitoring dimensions are relevant to IT ADM outsourcing, and why are these dimensions relevant?

- [RQ 2] Which minimum set of IT ADM standard KPIs could be derived to monitor suppliers?

- [RQ 3] How and why are these KPIs utilized?

To answer these research questions, we conducted a qualitative case study (Yin, 2003) to investigate the multisourcing relationships of a leading global financial service provider (hereafter referred to as organization ALPHA) and applied expert inter-rater reliability (Lawshe, 1975) to derive a minimum set of IT ADM KPIs to help practitioners monitor suppliers. Thus, this article aims to contribute to both theory and practice in the context of IT outsourcing and AIS in different ways. First, it contributes to the understanding of how large corporations monitor IT ADM suppliers by describing a real-life monitoring approach and its constituents. Second, this article derives relevant monitoring dimensions based on cross-case analysis. Third, based on inter-rater reliability, a minimum set of IT ADM KPIs is suggested. Finally, this research contributes to the understanding of why specific KPIs are employed by identifying monitoring objectives and proposing a model of effective monitoring IT ADM suppliers in multisourced environments. The theoretical contribution is mainly derived from the article's nature as a theory specification case in the context of the theory refinement phase. Keating (1995) suggests a classification of case research in management accounting to assess the theoretical (and practical) contribution. Hence, Keating (1995, p.68) states that the "research scope of a case study may be identified with one (or more) of the 3 stages of the theory development process - theory discovery, theory refinement, and theory refutation." Therefore, the following 4 distinct types of case studies can be differentiated (Keating, 1995): theory discovery, theory illustration, theory specification and crucial test/counterpoint. The article seeks to refine and operationalize the existing theory by specifying the (IT) BSC concept as well as the established IT frameworks by incorporating the empirical findings. Thus, the article, to some extent, provides novelty as well as significant theoretical/practical analysis and additionally comprises elements of a theory discovery case (Keating, 1995).

This research study is also expected to help corporations facing challenges in managing and monitoring IT ADM suppliers, thereby contributing to practitioner needs as well. The insights into a real-life example 
of monitoring IT ADM suppliers, the proposed dimensions and the suggested minimum set of IT ADM KPIs can be easily adopted in any company-specific IT ADM situation.

The remainder of this paper consists of 5 sections. Section 2, the next section, provides an overview of the fundamental terms used. Section 3 outlines the research methodology. Section 4 illustrates the empirical data and derives monitoring dimensions, a minimum set of corresponding IT ADM KPIs, as well as a model of effective monitoring. In Section 5, we discuss the research findings before we conclude in Section 6.

\section{Foundation and related research}

In any field of research, it is important to determine a common understanding of the basic terms. For this reason, Zorn and Campbell (2006) suggest the provision of key terms. Based on a literature review, we provide an introduction to multisourcing and to monitoring IT ADM suppliers.

\subsection{IT ADM in a multisourcing context}

While the basic concept of multiple suppliers ${ }^{5}$ is not new (see inter alia Porter (1985)), the concept of multisourcing focuses on services rather than on goods and is mainly concerned with the relationships between the client organization and the multiple suppliers (Levina and $\mathrm{Su}, 2008$ ). The definition of the multisourcing concept consists of the utilization of services from multiple company-internal (such as captive offshore centers ${ }^{6}$ ) and company-external suppliers in the pursuit of business goals (Cohen and Young, 2006).

The main driver behind the emergence of multisourcing strategies has been companies' increased need for cost efficiency, flexibility, speed and quality in a dynamic and global business environment (Levina and Su, 2008; Su and Levina, 2011). When applying multisourcing, companies face both opportunities and threats. On the one hand, companies strive to improve their flexibility and quality, to gain access to specialized expertise and capabilities, to obtain best-of-breed services and to foster competition between suppliers, thereby mitigating risks or reducing costs (Porter, 1985; McMillan, 1990; Richardson, 1993; Cross, 1995; Lacity and Willcocks, 1998; Bapna et al., 2010). On the other hand, multisourcing may require the operational model to be adapted, sets high prerequisites for managerial capabilities and entails extensive requirements in terms of governance and performance measurement (Cohen and Young, 2006; Levina and Su, 2008; Bapna et al., 2010).

According to Grover et al. (1996, p.106), IT ADM encompasses "systems analysis, design, and construction of application software and the accompanying software maintenance." It is mainly project-related and requires a high degree of interaction (Faraj and Sproull, 2000; Beulen et al., 2005). In contrast, infrastructure operations - which include system operations, telecommunications and end-user support - can be described as a continuous service (Grover et al., 1996; Beulen et al., 2005). Beulen et al. (2005, p.135) describe infrastructure operations as "preventative and remedial services that physically repair or optimize computing and communications hardware." In ADM, the high degree of interaction, combined with the management and monitoring of suppliers, requires significant managerial capabilities and comprises one of the major challenges in multisourcing. Thereby, IT ADM can be further differentiated into the sub-functions application development (AD) and application maintenance (AM) (see inter alia Dibbern (2004)).

\subsection{Monitoring suppliers}

Management, AIS and IS scholars agree that governance and performance measurement are important factors in IT outsourcing (McFarlan and Nolan, 1995; Langfield-Smith and Smith, 2003; Smith et al., 2005; Busi and Mclvor, 2008; Weimer and Seuring, 2009). By way of example, Clark et al. (1995, p.234) state that "the truly critical success factors associated with successful outsourcing are those associated with vendor governance." This statement is in line with the findings of Gottschalk and Solli-Sæther (2005) that

\footnotetext{
5 The terms vendor and supplier are used synonymously.

${ }^{6}$ Oshri et al. (2009, p.196) describe captive offshore centers as "wholly-owned subsidiaries located in an offshore location that perform work for the parent company."
} 
continuous governance and performance measurement are highly relevant to IT outsourcing success. Research on contractual governance (see inter alia Poppo and Zenger (2002)), service level agreements (SLAs) (see inter alia Goo et al. (2009)), strategic alliances (see inter alia McFarlan and Nolan (1995) or Das and Teng (2001)) and control mechanisms (see inter alia Kirsch et al. (2002)) has, to some extent, targeted the relationship between client organizations and suppliers and respective controls; however, very little experience-based research has investigated how corporations monitor suppliers in a multisourcing context in general and with regard to IT ADM suppliers in particular. Das and Teng (2001) as well as Langfield-Smith and Smith (2003) emphasize the importance of controls in IT outsourcing. According to Das and Teng (2001), control is associated with the process of monitoring. In principle, control can be divided into formal and informal controls (Ouchi and Maguire, 1975; Eisenhardt, 1985), with monitoring suppliers relating to formal controls.

Based on a literature review, we identified 4 IT frameworks and 2 effort estimation models that could be applied to monitor IT ADM suppliers. The selection criteria for these frameworks were scientific acknowledgment and practical relevance. In terms of scientific acknowledgment, IT frameworks that have been published and frequently cited in academic IS journals were considered for analysis (see Looso et al. (2011) and Google Scholar for the number of citations). Practical relevance was based on the frameworks' origin and adoption by practitioners. The IT frameworks and effort estimation models have a strong anchor in practice. Table 1 describes the frameworks analyzed according to the dimensions of origin, scope, number/focus of KPIs and relevance.

Our analysis of these frameworks suggests that they are either limited with regard to one certain aspect (particularly cost estimation) or are far too extensive in the number of KPIs and hence cannot be adopted straightforwardly by practitioners to monitor IT ADM suppliers. The findings of the analysis indicate that COBIT, VAL IT and ITIL provide numerous KPIs for various dimensions, but they do not recommend a specific set of KPIs that should be adopted to monitor suppliers in IT ADM. COCOMO and function point analysis are particularly dedicated to software engineering; however, they provide only a mathematical model and are focused solely on effort estimation. These findings indicate a gap in the existing body of knowledge that we intend to target with this research study. Therefore, we applied the principles of the BSC concept as suggested by Kaplan and Norton (1996) and Van Grembergen et al. (2004), who transferred the BSC concept to the IS function and derived an IT BSC. In particular, we adopted the claim that there are a finite number of KPIs, a balanced set of dimensions, while not limiting the view on the financial aspects (such as cost estimation) and cause-effect relations. While the BSC and the IT BSC are limited to company-internal performance measurement, we extend the concept to include the relationship between

Table 1

Overview of IT frameworks.

\begin{tabular}{|c|c|c|c|c|c|c|}
\hline Framework & COBIT 4.1 & VAL IT 2.0 & ITIL V3 & CMMI-DEV V3 & сосомо & FPA \\
\hline Name & $\begin{array}{l}\text { Control objectives } \\
\text { for information } \\
\text { and related } \\
\text { technology }\end{array}$ & $\begin{array}{l}\text { The Val IT } \\
\text { framework }\end{array}$ & $\begin{array}{l}\text { Information } \\
\text { technology } \\
\text { infrastructure } \\
\text { library }\end{array}$ & $\begin{array}{l}\text { Capability } \\
\text { maturity model } \\
\text { integration for } \\
\text { development }\end{array}$ & $\begin{array}{l}\text { Constructive cost } \\
\text { model }\end{array}$ & $\begin{array}{l}\text { Function point } \\
\text { analysis }\end{array}$ \\
\hline Origin & ITGI (2007) & ITGI (2008) & $\begin{array}{l}\text { Taylor et al. } \\
\text { (2007a, 2007b, } \\
\text { 2007c, 2007d, } \\
2007 e)\end{array}$ & SEI (2010) & Boehm (1981) & Albrecht (1979) \\
\hline Scope & $\begin{array}{l}\text { Best-practice } \\
\text { framework } \\
\text { encompassing } 34 \\
\text { IT processes and } \\
\text { corresponding } \\
\text { control objectives }\end{array}$ & $\begin{array}{l}\text { Framework } \\
\text { enabling the } \\
\text { creation of } \\
\text { business value } \\
\text { from IT-enabled } \\
\text { investments }\end{array}$ & $\begin{array}{l}\text { Best-practice } \\
\text { framework for } \\
\text { IT service } \\
\text { management }\end{array}$ & $\begin{array}{l}\text { Reference model, } \\
\text { primarily applied } \\
\text { in software } \\
\text { development }\end{array}$ & $\begin{array}{l}\text { Algorithmic } \\
\text { software cost } \\
\text { estimation } \\
\text { model }\end{array}$ & $\begin{array}{l}\text { Size-based } \\
\text { software cost } \\
\text { estimation } \\
\text { model }\end{array}$ \\
\hline KPIs & $\begin{array}{l}\text { Numerous KPIs } \\
\text { along } 34 \text { IT } \\
\text { processes }\end{array}$ & $\begin{array}{l}\text { Numerous KPIs } \\
\text { along } 3 \text { VAL IT } \\
\text { domains }\end{array}$ & $\begin{array}{l}\text { Numerous KPIs } \\
\text { along } 5 \text { ITIL } \\
\text { dimensions }\end{array}$ & $\begin{array}{l}\text { Exemplary } \\
\text { measures, yet no } \\
\text { specified KPIs }\end{array}$ & $\begin{array}{l}\text { KPIs not } \\
\text { specified - model } \\
\text { as a basis for KPIs }\end{array}$ & $\begin{array}{l}\text { KPIs not } \\
\text { specified - model } \\
\text { as a basis for KPIs }\end{array}$ \\
\hline Relevance & \multicolumn{4}{|c|}{$\begin{array}{l}\text { Focus on COBIT, VAL IT, ITIL and CMMI suggested by other IS researchers } \\
\text { (see inter alia Looso et al. (2011, p.93)) }\end{array}$} & $\begin{array}{l}\text { More than } 6000 \\
\text { citations }\end{array}$ & $\begin{array}{l}\text { Approx. } 1000 \\
\text { citations }\end{array}$ \\
\hline
\end{tabular}


a client organization and multiple external suppliers and follow the claim of Weimer and Seuring (2009) that the concept can be applied to governing and controlling suppliers.

\section{Research methodology}

To answer the research questions, we chose a 2-step research methodology. First, we conducted a cross-case study to investigate a real-life example of the monitoring of IT ADM suppliers in a multisourcing context. Second, we synthesized a framework with a minimum set of corresponding IT ADM KPIs based on expert inter-rater reliability.

\subsection{Cross-case study}

To gather in-depth data on how an international corporation manages and monitors suppliers in a multisourcing context, we conducted a cross-case study according to the guidelines provided by Patton (2002) and Yin (2003). Case studies are used to investigate complex phenomena (such as multisourcing) and are an established research design for qualitative research in IS (Benbasat et al., 1987; Palvia et al., 2007). In accordance with Eisenhardt (1989), who recommends using 4 to 10 cases, we conducted a cross-case study of organization ALPHA encompassing 7 independent business entities, with each business entity representing one individual case. The unit of analysis was the approach used by each individual business entity to monitor IT ADM suppliers in a multisourcing context (Yin, 2003). Table 2 provides an overview of the 7 cases in organization ALPHA and indicates supplementary documents provided by the interviewees.

Organization ALPHA, a leading global financial service provider, was selected because of the complexity of its multisourcing and the large number of business entities involved in the business group structure. Levina and $\mathrm{Su}$ (2008) argue that financial service providers tend to be more proactive in outsourcing and offshoring IT and business processes. To gather detailed information about organization ALPHA's approaches to monitoring, we conducted multiple interviews with representatives of 7 independent business entities (business entities A through $\mathrm{G}$ ) within the organization ALPHA. We selected business entities from different regions of the world (Europe, America and Asia) that focus on diverse lines of business (insurance and banking).

The data collection process was carried out over a 2-month period from August to September 2010. Each interview lasted between one and $2 \mathrm{~h}$. The interview guidelines consisted of general questions on the (multi)sourcing approach used by the business entities, as well as specific questions on managing and monitoring suppliers. For the purposes of data collection and analysis, the guidelines suggested by Glaser and Strauss (1967) were adopted. Thus, we intertwined data collection and analysis by developing the interview guidelines based on the previous interviews (theoretical sampling).

For data analysis, we applied cross-case analysis and traditional open coding (Corbin and Strauss, 1990; Patton, 2002). The qualitative data were organized according to the questions of the interview guidelines. Answers from different interviewees were grouped together, as suggested by Patton (2002). To identify coding categories, specific attention was paid to dimensions and KPIs applied by the individual cases, as well as drivers for these particular dimensions and KPIs. To avoid redundancies, we validated the KPI terms

Table 2

Overview of cases.

\begin{tabular}{|c|c|c|c|c|}
\hline Case & $\begin{array}{l}\text { Number of } \\
\text { interviews }\end{array}$ & $\begin{array}{l}\text { Total duration } \\
\text { (hours) }\end{array}$ & Role of interviewee & Supplementary key documents \\
\hline A & 3 & 3.5 & CIO, IT controller, ADM manager & Monitoring approach, list of KPIs \\
\hline B & 2 & 2 & $\mathrm{CIO}, \mathrm{ADM}$ manager & $\begin{array}{l}\text { List of KPIs, sample KPI report as provided by } \\
\text { IT ADM suppliers }\end{array}$ \\
\hline C & 2 & 2.5 & IT controller, ADM manager & Monitoring approach, list of KPIs \\
\hline $\mathrm{D}$ & 1 & 1 & $\mathrm{CIO}$ & List of KPIs \\
\hline E & 2 & 2.5 & ADM manager & Monitoring approach, list of KPIs \\
\hline $\mathrm{F}$ & 2 & 3.5 & ADM manager & Monitoring approach, list of KPIs \\
\hline G & 2 & 2 & IT controller & List of KPIs \\
\hline
\end{tabular}


with the current literature and aggregated similar KPIs under one term. In addition to the interview transcripts, we were granted access to key documents describing the monitoring approach and the KPIs that were applied (please refer to Table 2). These supplementary data enabled the use of triangulation (Patton, 2002; Denzin, 2009). We applied both triangulation of sources and analyst triangulation to ensure consistency (Patton, 2002). By triangulating the interview transcripts with the supplementary key documents, we were able to triangulate the sources. With 2 researchers to review the transcripts and documents, we utilized analyst triangulation.

The output of this research step was twofold. First, we were able to identify numerous KPIs that are applied in the case organization to monitor IT ADM suppliers and to map them to the respective cases (see Section 4.2). The result was an extensive list of potential KPIs that are applied in practice to monitor IT ADM suppliers. Second, the cross-case study allowed us to derive 6 relevant IT ADM supplier monitoring dimensions that are recommended for coverage (see Section 4.3).

\subsection{Expert inter-rater reliability}

To derive a minimum set of IT ADM KPIs, we adopted Lawshe's content validation technique (Lawshe, 1975). Lawshe's technique is applied to quantify the consensus of experts. Hence, we utilized persons knowledgeable in the field of monitoring IT ADM suppliers to evaluate the 47 KPIs derived from the crosscase study. Lawshe (1975) emphasizes the importance of who is judging and suggests that "subject-matter experts are generally perceived as true experts" (Lawshe, 1975, p.565). In our case, the experts were selected based on their special knowledge about the subject; they represented 2 of the worldwide leading ADM outsourcing providers (BETA and GAMMA), one leading India-based ADM outsourcing provider (DELTA) and a leading consulting firm specializing in IT performance management (EPSILON). Additionally, representatives of organization ALPHA's group center, responsible for sourcing and controlling, were selected. The latter are independent from the 7 cases, yet knowledgeable about managing and monitoring IT ADM suppliers. Table 3 provides an overview of the content evaluation panel. The selected experts have an average of 11 years of relevant experience.

The panel was carried out in person during 3 independent workshops in October and November 2010. Each expert (on the content evaluation panel) was provided with the same list of KPIs and the respective descriptions and was asked to respond to the following question regarding each KPI:

Is this KPI (1) a "must-have" KPI; (2) a "nice-to-have" KPI; or (3) "not required" to monitor IT ADM suppliers in a multisourcing context?

Using this approach, Lawshe's (1975) original question was modified slightly to meet the requirements of evaluating the essentiality of IT ADM KPIs. Lawshe (1975) distinguishes "essential," "useful but not essential" and "not necessary." For our panel, "must-have" represents "essential," "nice-to-have" represents "useful but not essential" and "not required" represents "not necessary." This modification is justified to adapt the approach to the KPIs under investigation. To derive a minimum set of IT ADM KPIs, we focused on the

Table 3

Overview of content evaluation panel.

\begin{tabular}{lllr}
\hline Expert & Affiliation & Role of expert & $\begin{array}{c}\text { Years of relevant } \\
\text { experience }\end{array}$ \\
\hline 1 & Group center of organization ALPHA & Head of IT multisourcing & 12 \\
2 & Group center of organization ALPHA & Vendor manager & 6 \\
3 & Group center of organization ALPHA & Head of IT controlling & 10 \\
4 & Global ADM outsourcing provider BETA & Associate partner & 15 \\
5 & Global ADM outsourcing provider BETA & Customer reporting manager & 7 \\
6 & Global ADM outsourcing provider GAMMA & Executive partner & 18 \\
7 & India-based ADM outsourcing provider DELTA & Head of financial services (Europe) & 13 \\
8 & India-based ADM outsourcing provider DELTA & Relationship manager & 8 \\
9 & Consulting firm EPSILON specializing in IT performance & Senior consultant & 10 \\
& management & & \\
\hline
\end{tabular}


essential KPIs as suggested by Lawshe (1975). The responses were pooled, and the number indicating "must-have" (essential) for each KPI was determined. Based on these findings, we calculated both the content validation ratio (CVR) of each KPI and the content validation index (CVI) of the selected minimum set of IT ADM KPIs. The CVR is calculated as follows:

$$
\mathrm{CVR}=\frac{\mathrm{n}_{\mathrm{e}}-\frac{\mathrm{N}}{2}}{\frac{\mathrm{N}}{2}}
$$

in which $\mathrm{n}_{\mathrm{e}}$ is the number of experts indicating a "must-have" KPI and $\mathrm{N}$ is the total number of experts. The CVR follows the principle that the more experts who perceive a KPI as essential ("must-have"), the greater is the degree of content validity. To eliminate KPIs for which concurrence might occur by chance, we follow Lawshe's suggestion to apply the 5-percent rule (Lawshe, 1975, p.568). With a total number of 9 experts in the content evaluation panel, we derive a minimum CVR value of 0.78 for a KPI to remain in the final minimum set of KPIs (Lawshe, 1975, p.571). Beyond the CVR, the CVI is defined as the simple mean of all CVRs of the KPIs not eliminated (Lawshe, 1975). The results are presented in Section 4.4.

\section{Empirical data}

\subsection{Multisourcing relationships in the case organization}

Organization ALPHA is one of the world's leading financial service providers. It can best be described as a multinational business group with a group center and numerous, legally independent business entities that the group center manages. The group center in organization ALPHA does not assume any operational responsibility, as is frequently prevalent in business group organizations (Hodgkinson, 1996). With regard to IS functions, organization ALPHA is characterized by a decentralized organizational approach, with both a group chief information officer (CIO) and local CIOs for the individual business entities, as well as a federal model of IT governance.

In terms of sourcing IT ADM, organization ALPHA follows a group-wide multisourcing strategy. With a limited number of globally preferred external suppliers, organization ALPHA has entered into a groupwide framework agreement with regard to IT ADM services. Each independent business entity can engage with one or more of the preferred IT ADM suppliers. In addition, the business entities also source from specialized local suppliers. Each business entity can decide upon its sourcing activities and therefore possesses an individual set of suppliers. Basically, the business entities are urged to source from the globally preferred suppliers. However, a business entity might source from a local specialized supplier, for example, in the case of special language skills or application knowledge. The exemplary multisourcing relationships in organization ALPHA are illustrated in Fig. 1.

\subsection{Monitoring IT ADM suppliers in organization ALPHA}

The supplier monitoring activities in organization ALPHA mainly affect the relationship between the various business entities and the numerous external suppliers. The business entities are those organizational units of organization ALPHA that obtain the IT ADM services from the external suppliers and therefore need to control the respective performance. In contrast to the business entities, the group center does not obtain IT ADM services; however, it monitors the external providers on a generic level. The external providers are asked to report sourcing volumes, efforts and offshoring ratios to the group CIO. Nevertheless, the operational monitoring of the external IT ADM suppliers is carried out by the business entities (referring to exemplary relationships between business entities and suppliers in Fig. 1).

Monitoring IT ADM suppliers in the business entities in organization ALPHA is accomplished by mutually agreed KPIs. Both the client (business entity of organization ALPHA) and the respective suppliers agree on a specific set of KPIs to be reported by the suppliers to the business entities. In response to the question of how the business entity monitors suppliers, one interviewee stated:

"The answer is very straightforward in that we monitor [supplier n] in terms of a mutually defined set of KPIs." 


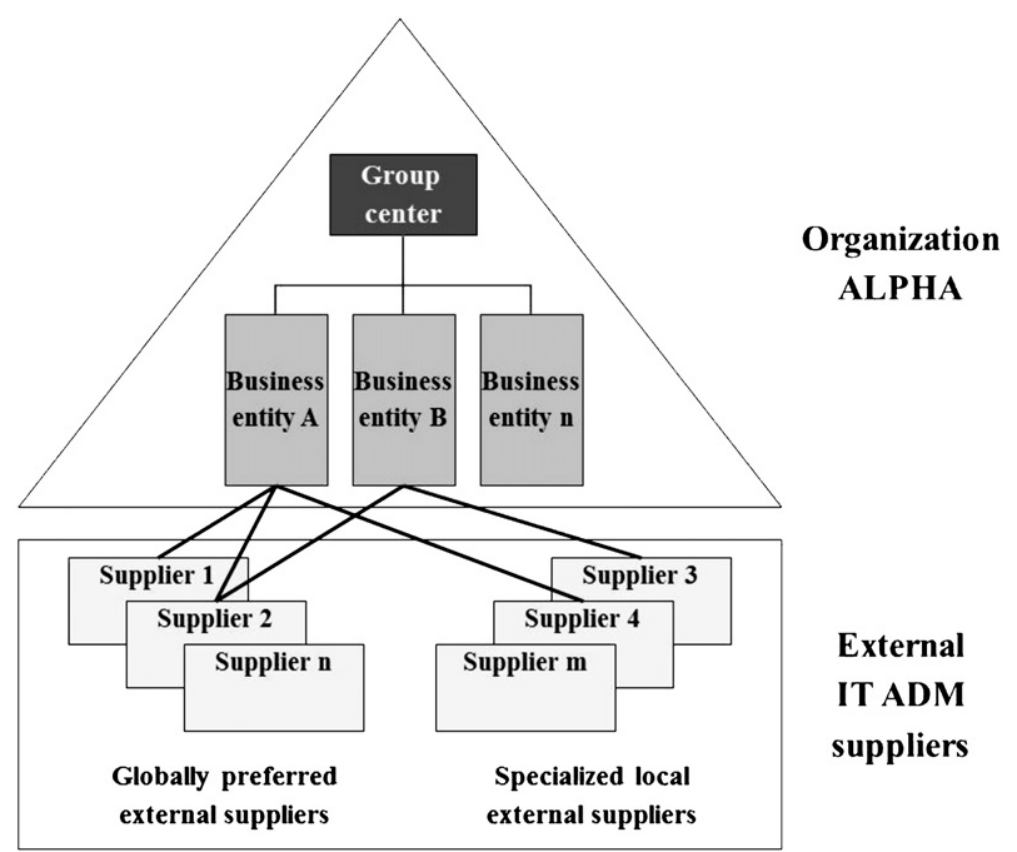

Fig. 1. Exemplary multisourcing relationships in organization ALPHA.

However, the cases indicate that even within one business entity, no consistent set of KPIs is employed for different suppliers performing a similar activity or the same activity. The case study interviewees argue that this practice is based on historical reasons and individual negotiations with the different suppliers. The same scenario is true for the format of reporting. We identified various approaches from spreadsheets (mainly MS Excel) and presentations (mainly MS PowerPoint) to integrated systems (e.g., ticketing systems). Each business entity makes a considerable effort to gather, consolidate and prepare the various KPIs from different suppliers. The responsibility throughout the cases lies with the vendor management of the respective business entities. The complement at the supplier site is either the account manager (or a delegate of his/her team) or the supplier's project management office, which is established for large projects with organization ALPHA. An interviewee stated, for example:

"From a supplier perspective, the metrics are maintained by the [supplier $\mathrm{n}$ ] project management office, who is our counterpart in monitoring aspects."

The cross-case analysis reveals further that to date [the time of the case study interviews], there is no bottom-up reporting of operational IT ADM KPIs from the local business entities to the group center. The reason for this is clearly addressed by one manager:

"Operational KPIs [in IT ADM] have to be implemented locally since these KPIs are becoming more and more meaningless when they are aggregated."

Accordingly, the expert supports the limitation of our research study to IT ADM:

"Monitoring aspects of project-related outsourcing endeavors should be considered separately from those of infrastructure outsourcing."

With regard to the frequency of delivering KPIs, all of the investigated business entities follow defined reporting cycles. The reporting cycles vary between weekly, monthly and quarterly reporting. The majority of KPIs are reported on a monthly basis. A few KPIs are collected on a quarterly basis, including customer 
satisfaction surveys or lessons learned. Operational KPIs, such as incident reporting, are tracked on a weekly basis. One manager stated:

"The objective [of the weekly reporting] is to have a more operational follow-up on how [supplier n] is performing in incident resolution."

Further, we observed that the business entities apply different terms for the same or similar KPIs. This observation was confirmed throughout the case study interviews by most of the interviewees:

"[Within organization ALPHA], there is no common set of KPIs or uniform definitions ready to use in order to manage and monitor suppliers across the group in a common way."

An explanation for this finding is related to the fact that in organization ALPHA, the distinct business entities are responsible for defining and monitoring IT ADM KPIs, and operational IT ADM KPIs are not aggregated at the group level. Further, the decentralized structure and the federal governance mode do not facilitate alignment between the business entities in this regard. Additionally, best practices are rare. This observation is also supported by the following statement from an interviewee:

"There are numerous KPIs available - loosely listed or comprised in frameworks - and we have already implemented some, and yet we are still missing recommendations regarding which essential ones should be considered."

Based on the cross-case study and the analysis of the accompanying documents provided, we were able to identify $47 \mathrm{KPIs}$ that are applied in the various business entities of organization ALPHA to monitor IT ADM suppliers. Table 4 illustrates how the different business entities approach supplier monitoring in organization ALPHA in regard to KPIs. The matrix summarizes the observed KPIs (on the vertical axis) and maps them to each of the analyzed cases (on the horizontal axis). The first column of Table 4 states the term of the KPIs. In the second column, we provide the ADM sub-function to which the KPI is related (see Appendix 1 for descriptions of KPIs). Regarding the ADM sub-functions, the cross-case study suggests a distinction between monitoring AD and AM because the majority of the KPIs are utilized for only one ADM sub-function. Only the following 7 KPIs out of all 47 identified KPIs are utilized for monitoring both ADM sub-functions (AD and $\mathrm{AM}$ ): budget compliance ratio, satisfaction index, attrition rate, competence index, retention of key supplier staff, staffing level (role) and staffing level (location). Using these results, we distinguish the following 3 types of KPIs: (1) KPIs that can be explicitly allocated to AD; (2) KPIs that can be explicitly allocated to AM; and (3) KPIs that can be allocated to AD and AM (illustrated as AD/AM in Table 4).

Further, of all 47 KPIs, 4 were encountered across all 7 cases, namely time compliance, budget compliance, customer satisfaction and availability of applications, while functional compliance was applied 6 times. One interviewee stated:

"Time, budget, function and availability are absolute standard KPIs you must adopt while monitoring ADM suppliers. In addition, you should gather feedback directly from customers."

Moreover, within organization ALPHA, we found that the distinction between incident and problem management, as suggested, for example, by the ITIL (OGC, 2007), was not adopted properly across the group. One interviewee stated:

"For reasons of simplification, we do not differentiate between incident and problem management; we use the terms synonymously."

This statement indicates that business entities within large, multinational corporations with a decentralized IT organization can demonstrate different levels of maturity in terms of adopting IT best-practice frameworks.

\subsection{Developing relevant IT ADM supplier monitoring dimensions}

Sourcing IT ADM work to multiple suppliers results in a loss of direct control over at least certain activities of the IT ADM process; therefore, a client organization seeks to monitor its suppliers along 
Table 4

Overview of the cases and list of applied KPIs (sorted by prevalence and alphabetically).

\begin{tabular}{|c|c|c|c|c|c|c|c|c|}
\hline \multirow[t]{2}{*}{ KPI } & \multirow[t]{2}{*}{ ADM sub-function } & \multicolumn{7}{|c|}{ Case } \\
\hline & & A & B & C & $\mathrm{D}$ & $\mathrm{E}$ & $\mathrm{F}$ & G \\
\hline Availability of application & $\mathrm{AM}$ & $\mathrm{x}$ & $\mathrm{x}$ & $\mathrm{x}$ & $\mathrm{x}$ & $\mathrm{x}$ & $\mathrm{x}$ & $\mathrm{x}$ \\
\hline Budget compliance ratio & $\mathrm{AD} / \mathrm{AM}$ & $\mathrm{x}$ & $\mathrm{x}$ & $\mathrm{x}$ & $\mathrm{x}$ & $\mathrm{x}$ & $\mathrm{x}$ & $\mathrm{x}$ \\
\hline Satisfaction index & $\mathrm{AD} / \mathrm{AM}$ & $\mathrm{x}$ & $\mathrm{x}$ & $\mathrm{x}$ & $\mathrm{x}$ & $\mathrm{x}$ & $\mathrm{x}$ & $\mathrm{x}$ \\
\hline Time compliance ratio & $\mathrm{AD}$ & $\mathrm{x}$ & $\mathrm{x}$ & $\mathrm{x}$ & $\mathrm{x}$ & $\mathrm{x}$ & $\mathrm{x}$ & $\mathrm{x}$ \\
\hline Functional compliance ratio & $\mathrm{AD}$ & $\mathrm{x}$ & $\mathrm{x}$ & & $\mathrm{x}$ & $\mathrm{x}$ & $\mathrm{x}$ & $\mathrm{x}$ \\
\hline Defect removal index & $\mathrm{AD}$ & $\mathrm{x}$ & $\mathrm{x}$ & & $\mathrm{x}$ & & $\mathrm{x}$ & $\mathrm{x}$ \\
\hline Incident resolution time & $\mathrm{AM}$ & $\mathrm{x}$ & $\mathrm{x}$ & $\mathrm{x}$ & & $\mathrm{x}$ & $\mathrm{x}$ & \\
\hline Incident response time & AM & $\mathrm{x}$ & $\mathrm{x}$ & $\mathrm{x}$ & & $\mathrm{x}$ & $\mathrm{x}$ & \\
\hline Incidents per severity level & $\mathrm{AM}$ & & $\mathrm{x}$ & & $\mathrm{x}$ & $\mathrm{x}$ & $\mathrm{x}$ & $x$ \\
\hline Attrition rate & $\mathrm{AD} / \mathrm{AM}$ & $\mathrm{x}$ & $\mathrm{x}$ & & & $\mathrm{x}$ & $\mathrm{x}$ & \\
\hline Defect density & $\mathrm{AD}$ & & $\mathrm{x}$ & & $\mathrm{x}$ & & $\mathrm{x}$ & $\mathrm{x}$ \\
\hline Defect distribution & $\mathrm{AD}$ & & $\mathrm{x}$ & & $\mathrm{x}$ & & $\mathrm{x}$ & $\mathrm{x}$ \\
\hline CMMI compliance & $A D$ & & & & & & $\mathrm{x}$ & $\mathrm{x}$ \\
\hline Cost per function point & $\mathrm{AD}$ & & $\mathrm{x}$ & & & & & $\mathrm{x}$ \\
\hline Defects per function point & $\mathrm{AD}$ & & $\mathrm{x}$ & & & & & $\mathrm{x}$ \\
\hline Function points per developer & $\mathrm{AD}$ & & $\mathrm{x}$ & & & & & $\mathrm{x}$ \\
\hline Function points per person day & $\mathrm{AD}$ & & $\mathrm{x}$ & & & & & $\mathrm{x}$ \\
\hline Incident backlog index & AM & & & $\mathrm{x}$ & & $\mathrm{x}$ & & \\
\hline Problem resolution time & AM & $\mathrm{x}$ & & & & $\mathrm{x}$ & & \\
\hline Recurring incidents & AM & & & $\mathrm{x}$ & & $\mathrm{x}$ & & \\
\hline Change request rejection ratio & AM & & & $\mathrm{x}$ & & & & \\
\hline Change requests after handover to production & $\mathrm{AM}$ & & & & & & $\mathrm{x}$ & \\
\hline Competence index & $\mathrm{AD} / \mathrm{AM}$ & & & & & & & $\mathrm{x}$ \\
\hline Cost of quality & $\mathrm{AD}$ & & & & & & & $\mathrm{x}$ \\
\hline Cost performance index & $\mathrm{AD}$ & & $\mathrm{x}$ & & & & & \\
\hline Defects per severity level & $\mathrm{AD}$ & & & & & & $\mathrm{x}$ & \\
\hline First-time incident resolution rate & AM & & $\mathrm{x}$ & & & & & \\
\hline Frequency of releases & $\mathrm{AM}$ & & & $\mathrm{x}$ & & & & \\
\hline Incidents per application & AM & & & & & & $\mathrm{x}$ & \\
\hline Incidents per problem ratio & AM & $\mathrm{x}$ & & & & & & \\
\hline Lessons learned & $\mathrm{AD}$ & & & & & & & $\mathrm{x}$ \\
\hline Number of emergency change requests & AM & & & $\mathrm{x}$ & & & & \\
\hline Problem backlog index & AM & & $\mathrm{x}$ & & & & & \\
\hline Problems per application & AM & $\mathrm{x}$ & & & & & & \\
\hline Problems per severity level & AM & & $\mathrm{x}$ & & & & & \\
\hline Project staffing & $\mathrm{AD}$ & $\mathrm{x}$ & & & & & & \\
\hline Rate at which changes introduce problems & $\mathrm{AM}$ & & $\mathrm{x}$ & & & & & \\
\hline Rate of change-related incidents & AM & & $\mathrm{x}$ & & & & & \\
\hline Rate of unauthorized change requests & AM & & $\mathrm{x}$ & & & & & \\
\hline Recurring problems & AM & & $\mathrm{x}$ & & & & & \\
\hline Rerouted incidents & $\mathrm{AM}$ & $\mathrm{x}$ & & & & & & \\
\hline Retention of key supplier staff & $\mathrm{AD} / \mathrm{AM}$ & & & $\mathrm{x}$ & & & & \\
\hline Risk status & $\mathrm{AD}$ & & & & & & $\mathrm{x}$ & \\
\hline Schedule performance index & $\mathrm{AD}$ & & $\mathrm{x}$ & & & & & \\
\hline Staffing level (role) & $\mathrm{AD} / \mathrm{AM}$ & & $\mathrm{x}$ & & & & & \\
\hline Staffing level (location) & $\mathrm{AD} / \mathrm{AM}$ & & $\mathrm{x}$ & & & & & \\
\hline Time compliance of releases & $\mathrm{AM}$ & & & $\mathrm{x}$ & & & & \\
\hline
\end{tabular}

different perspectives. The cross-case study in organization ALPHA reveals 6 relevant IT ADM supplier monitoring dimensions that we recommend should be covered when monitoring IT ADM multisourcing suppliers.

\subsubsection{Time}

This dimension and the related KPIs cover aspects relating to milestone adherence and responsiveness. Based on the interviews, we found that the IS function ADM is mainly project-driven and steered (for example) by project milestones and adherence to the same. This dimension can be, for instance, applied to penalize suppliers when they fail to meet the agreed deadlines. 


\subsubsection{Quality}

The quality of IT ADM work is primarily measured by defects (in AD) as well as incidents and problems (in AM). Further exemplary controls are functional compliance - the degree of AD projects delivered within scope - and the availability of applications (in AM). When outsourcing IT ADM work to a multitude of suppliers, quality monitoring has been identified as a crucial dimension, and KPIs are also applied to penalize suppliers when quality-related objectives are not met.

\subsubsection{Efficiency}

This dimension is important when appraising the work of suppliers and interrelating it to other dimensions, such as quality and budget. In this regard, for instance, function points are utilized as a control to measure efficiency (function points per developer or person day) and can be interrelated to the budget dimension (cost per function point) or quality dimension (defects per function point). The efficiency dimension allows a client company to measure how efficiently IT ADM suppliers perform and to compare them.

\subsubsection{Monetary}

All of the cases indicated that the monetary dimension is critical when monitoring and comparing multiple suppliers. The interviewees stated that ADM projects frequently run out of money, and for this reason, it is inevitable that budget compliance will be monitored on a regular basis. In case of deviations, the client organization must investigate the root cause. The deviation might occur based on inappropriate planning or unforeseen circumstances.

\subsubsection{Customer}

In the context of sourcing IT ADM work to multiple suppliers, the supplier management function has only limited insights into the actual service delivery of the IT ADM work packages, the daily collaboration between suppliers and the satisfaction of the end-customer with the realization of the IT ADM work. The collaboration between various suppliers is especially important in multisourced environments because of the interdependence of activities. For this reason, it is advisable to consider the customer's perceptions in this regard. Frequently, a standard questionnaire is utilized to gather customer feedback at the end of projects (such as $\mathrm{AD}$ ) or on a regular basis for ongoing activities (such as AM).

\subsubsection{People}

A client organization is advised to monitor the attrition rate of the external suppliers because this rate is a key success factor in outsourcing IT ADM work, according to Rajkumar and Mani (2001). In particular, offshore IT ADM suppliers tend to have higher attrition rates, resulting in a potential loss of knowledge.

\subsection{Toward a minimum set of IT ADM KPIs and a model of effective monitoring}

By applying Lawshe's content validation technique to the identified $47 \mathrm{KPIs}$, we derive a minimum set of IT ADM KPIs for a client organization seeking to monitor IT ADM suppliers. We propose 19 KPIs that fulfill the requirements established by Lawshe (1975). A total of 11 KPIs obtain a CVR of 0.99, whereas 8 KPIs obtain a CVR of 0.78 . The remaining KPIs are excluded from the minimum set of IT ADM KPIs. The CVI of the entire minimum set of IT ADM KPIs is 0.88. Table 5 illustrates the minimum set of IT ADM KPIs with corresponding ADM sub-functions, monitoring objectives, monitoring dimensions and CVRs (for CVRs of all KPIs, see Appendix 1).

The findings reveal that 3 KPIs of the minimum set can be applied to both ADM sub-functions (AD and AM). These KPIs are attrition rate, budget compliance ratio and satisfaction index. Hence, a client company may monitor suppliers' attrition rates for $\mathrm{AD}$ and $\mathrm{AM}$. The same is true for budget compliance as well as customer satisfaction with suppliers. The remaining 16 KPIs relate explicitly to one ADM sub-function either AD or AM (Table 5, column ADM sub-function).

To indicate why specific KPIs are utilized in monitoring IT ADM suppliers, we illustrate the objectives of the individual KPIs (Table 5, column monitoring objective). The 3 KPIs (attrition rate, budget compliance ratio and satisfaction index) associated with both ADM sub-functions pursue 3 discrete objectives. The KPI attrition rate monitors the suppliers' staff turnover and aims to retain knowledge with the suppliers. The KPI budget compliance ratio tracks the budget and cost adherence, aiming to identify deviations as soon as 
Table 5

Minimum set of KPIs for monitoring IT ADM suppliers (sorted by ADM sub-function and alphabetically).

\begin{tabular}{|c|c|c|c|c|}
\hline $\begin{array}{l}\text { ADM } \\
\text { sub-function }\end{array}$ & KPI & Monitoring objective & $\begin{array}{l}\text { Monitoring } \\
\text { dimension }\end{array}$ & $\mathrm{CVR}^{\mathrm{a}}$ \\
\hline $\mathrm{AD}$ & Defect density & Ensure a high level of application development process quality & Quality & 0.78 \\
\hline $\mathrm{AD}$ & Defect distribution & Ensure a high level of application development process quality & Quality & 0.78 \\
\hline $\mathrm{AD}$ & Defect removal index & Ensure a high level of application development process quality & Quality & 0.78 \\
\hline $\mathrm{AD}$ & $\begin{array}{l}\text { Function points per } \\
\text { person day }\end{array}$ & Ensure an efficient application development process & Efficiency & 0.78 \\
\hline $\mathrm{AD}$ & Functional compliance ratio & Ensure that the supplier meets the customer requirements & Quality & 0.99 \\
\hline $\mathrm{AD}$ & Time compliance ratio & Ensure time compliance and identify delays promptly & Time & 0.99 \\
\hline AM & Availability of application & Ensure business continuity & Quality & 0.99 \\
\hline $\mathrm{AM}$ & $\begin{array}{l}\text { Backlog index } \\
\text { (incidents, problems) }^{\mathrm{b}}\end{array}$ & Ensure efficient incident and problem management & Efficiency & 0.78 \\
\hline $\mathrm{AM}$ & $\begin{array}{l}\text { First-time incident } \\
\text { resolution rate }\end{array}$ & Ensure a high level of supplier resolution capability & Quality & 0.78 \\
\hline AM & Incident resolution time & Ensure a high level of supplier resolution capability & Time & 0.99 \\
\hline AM & Incident response time & Ensure a high level of supplier responsiveness & Time & 0.99 \\
\hline AM & Incidents per problem ratio & Ensure a high level of supplier resolution capability & Quality & 0.78 \\
\hline AM & Incidents per severity level & Ensure a high quality level of incident management & Quality & 0.99 \\
\hline AM & Problem resolution time & Ensure a high level of supplier resolution capability & Time & 0.99 \\
\hline AM & Problems per severity level & Ensure a high quality level of problem management & Quality & 0.99 \\
\hline AM & Recurring incidents & Ensure a high level of supplier resolution capability & Quality & 0.78 \\
\hline $\mathrm{AD} / \mathrm{AM}$ & Attrition rate & Retain knowledge with the supplier & People & 0.99 \\
\hline $\mathrm{AD} / \mathrm{AM}$ & Budget compliance ratio & Ensure budget compliance and identify deviations promptly & Monetary & 0.99 \\
\hline $\mathrm{AD} / \mathrm{AM}$ & Satisfaction index & $\begin{array}{l}\text { Gather direct customer feedback on satisfaction with the } \\
\text { supplier performance }\end{array}$ & Customer & 0.99 \\
\hline
\end{tabular}

a If all experts claim essential, then the CVR is adjusted to 0.99 for ease of manipulation (Lawshe, 1975, p.568).

b Listed in Table 4 as 2 distinct KPIs.

possible in the application life cycle or to leverage competition between the suppliers. The KPI satisfaction index illustrates customer satisfaction with suppliers, identifies concrete issues within a project or allows vendor management to collect soft factors related to suppliers, including the ease of cooperation. In contrast, the remaining KPIs target objectives relating to quality or efficiency. With the exception of the KPI time compliance ratio, which aims to ensure milestone adherence, all of the AD-related KPIs aim to ensure either the quality or the efficiency of the application development process. For AM-related KPIs, our observation is similar. In addition to the KPI availability of applications, which aims to ensure business continuity, all of the AM-related KPIs aim to ensure the quality, efficiency and responsiveness of suppliers' incident- and problem-management processes. With regard to the time perspective, the objectives differ in that the AD-related KPIs monitor the deviation from milestones compared with the responsiveness of the AM-related KPIs. The following major monitoring objectives can be identified: budget adherence, time compliance and responsiveness, quality and efficiency, while maintaining business continuity, customer satisfaction and knowledge retention.

While reducing the list to the essential KPIs - namely 19 IT ADM KPIs - by utilizing expert inter-rater reliability, the 6 suggested monitoring dimensions remain (see Section 4.3). For each of the suggested monitoring dimensions, at least one KPI per ADM sub-function remains in the minimum set of IT ADM KPIs, thereby endorsing the proposed dimensions. In combination with our findings in the cross-case study on monitoring objectives, we suggest a model for effectively monitoring IT ADM suppliers in multisourced environments (Fig. 2) based on the following proposition:

A defined set of monitoring dimensions - constituting time, quality, efficiency, monetary, customer, and people - enhances effective monitoring of IT ADM suppliers in multisourced environments.

In this context, the identified KPIs of the minimum set (see Table 5) represent, on the one hand, measures for the individual monitoring dimensions. For example, the dimension time can be operationalized by the KPIs time compliance ratio (in $\mathrm{AD}$ ) and incident resolution time, incident response time or problem resolution time (in AM). On the other hand, effective monitoring relates to the identified monitoring objectives that, in turn, 


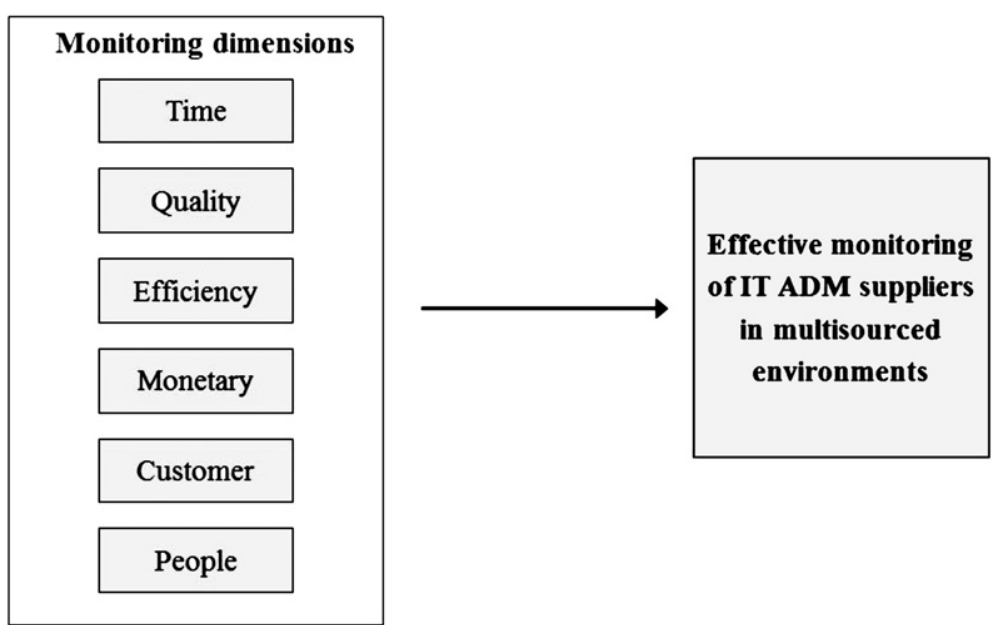

Fig. 2. Model of effective monitoring of IT ADM suppliers in multisourced environments.

support the superior multisourcing objectives identified earlier in this article. In particular, ensuring time compliance and responsiveness (monitoring dimension: time) contributes mainly to the multisourcing objective of risk mitigation and speed. Pursuing budget adherence (monitoring dimension: monetary) primarily supports the multisourcing objective associated with costs. Enhancing quality and efficiency while maintaining business continuity (monitoring dimensions: quality and efficiency) promotes companies' ambition to improve flexibility and quality and to obtain best-of-breed services for the company-internal customers of the IT department. The latter applies to ensuring customer satisfaction as well (monitoring dimension: customer). Finally, retaining knowledge (monitoring dimension: people) sustains access to specialized expertise and capabilities.

\section{Discussion}

Smith et al. (2005) describe the important role of management accounting in managing outsourcing relationships in general and in measuring outcomes in particular. Langfield-Smith and Smith (2003) argue in this regard that control systems support the success of IT outsourcing, which is in line with the claim of McFarlan and Nolan (1995) that performance measurement is critical to outsourcing success. While multisourcing proves to be a dominant sourcing strategy (Levina and Su, 2008; Bapna et al., 2010; Oshri et al., 2011) and the body of knowledge on IT outsourcing is growing, there are few accounts relating to monitoring suppliers in an IT multisourcing context. Although best-practice IT frameworks such as COBIT and ITIL provide some metrics, these frameworks fall short of describing how large corporations monitor IT ADM suppliers. In addition, relevant monitoring dimensions and concrete KPIs are missing. By applying cross-case analysis, this research study addresses this gap and describes how business entities in one of the world's leading financial service providers monitor IT ADM suppliers, KPIs utilized and the reasons why. Hence, 6 relevant monitoring dimensions are derived. By applying Lawshe's content validation technique, we derive a minimum set of "essential" IT ADM KPIs (Lawshe, 1975). According to the 5-percent rule, only those KPIs with a CVR of 0.78 or greater remain in the final set (Lawshe, 1975, p.568). Based on the monitoring dimensions and the identified monitoring objectives, which are interrelated to superior multisourcing objectives, we propose a model of effective monitoring IT ADM suppliers in multisourced environments.

The proposed model follows the principles of BSCs as an instrument of performance measurement, that is, a balanced set of dimensions that does not limit the view of financial aspects, a cause-effect relation and a finite number of KPIs (Kaplan and Norton, 1996; Weimer and Seuring, 2009). Our research derives 6 dimensions recommended for coverage when monitoring IT ADM suppliers in multisourced environments. The traditional BSC, according to Kaplan and Norton (1996), covers the financial, internal business process, customer, and learning and growth dimension. The IT BSC proposed by Van Grembergen et al. 
(2004) constitutes business contribution, user orientation, operational excellence, and future orientation as major dimensions. The proposed model extends the preliminary internal perspective of BSCs and IT BSCS to inter-company relationships with multiple suppliers for a given IS function (IT ADM). Consequently, the proposed dimensions (time, quality, efficiency, monetary, customer, and people) comprise and enhance the traditional BSC dimensions. In particular, the proposed monetary dimension represents the financial dimension of the BSC, and the customer dimension is adapted simultaneously. However, while monitoring IT ADM suppliers, customers are defined as internal customers of the IT department, and the finance dimension relates to monitoring and managing costs rather than revenues. The proposed people dimension relates to the learning and growth dimension of the traditional BSC concept; however, this dimension is not limited to internal staff but rather covers suppliers' personnel. The remaining 3 dimensions (time, quality, and efficiency) relate to the internal processes dimension of the traditional BSC but constitute the major difference between traditional BSCs and the proposed model. While the scope of the traditional BSC is limited on internal processes, multisourcing IT ADM entails a loss of direct control over this IS function or particular activities of this process. Taking this factor into account, our model aims to provide means for a client organization to monitor and manage concerned suppliers. In this regard, our research identifies 3 relevant dimensions (time, quality, and efficiency), as indicated in our cross-case study. This extension of the traditional BSC concept is in line with Kaplan and Norton's (1996) argument that depending on certain contingencies, one or more additional dimensions are needed. The extension also aligns with the findings of Weimer and Seuring (2009) on utilizing the BSC for controlling suppliers. Our research further indicates a positive relationship between the monitoring dimensions (with respective KPIs as measures) and effective monitoring IT ADM suppliers in multisourced environments. This relationship is supported by both our cross-case study findings and the inter-rater reliability results. The case study participants concur that to exploit the benefits of multisourcing, supplier monitoring objectives are linked to superior multisourcing objectives and measured along the identified dimensions by selected IT ADM KPIs. To limit the number of KPIs (another principle of BSC concepts) and to address practitioners' claim for a recommendation of essential IT ADM KPIs, we apply inter-rater reliability. The results of the content evaluation panel support the findings of the cross-case study by identifying at least one KPI per ADM sub-function as essential for each monitoring dimension. While comparing the final minimum set of IT ADM KPIs with the KPIs utilized by the business entities in organization ALPHA (see Table 4), the results indicate that all of the KPIs utilized by at least 4 business entities - representing $57 \%$ of the cases - are also constituents of the minimum set of IT ADM KPIs. This result is true for 12 out of the 19 KPIs in the minimum set. Because the cross-case study is independent of the content validation panel, this finding further supports the validation of the minimum set. Beyond these 12 KPIs found in 4 out of 7 cases and suggested to be essential by the content evaluation panel, the subject matter experts propose an additional 7 KPIs to be integrated into the minimum set. By applying the 5-percent rule, we see strong evidence to follow this suggestion.

This research study aims to target how and why large corporations monitor IT ADM suppliers. Therefore, this research can be characterized as a contribution to type 2 theories on a lower, more operational level (theory of explaining - sub-type 2: low level), according to the classification of Gregor (2006). This type of theory aims to provide explanations for "how and why things happened in some particular real-world situation" (Gregor, 2006, p.624) and aims to "explain something that was poorly or imperfectly understood beforehand" (Gregor, 2006, p.625). Further, applying the taxonomy of Keating (1995) to case study research in management accounting, our findings are in line with a theory discovery case. By providing a degree of novelty as well as theoretically/practically significant analysis, this research consists of elements of a theory discovery case (Keating, 1995). Moreover, by incorporating empirical findings from a cross-case study of business entities in organization ALPHA and inter-rater reliability, this article seeks to refine and operationalize the existing theory (theory specification case). Keating (1995) reflects on this combination by stating that the scope of a case study can contribute to one or more stages of the theory development process. By proposing a model (see Section 4.4), this research describes a causeeffect relation between monitoring dimensions and effective monitoring IT ADM suppliers in multisourced environments. Hence, this article is not limited to explanation (theory of explaining according to Gregor (2006)); to some extent, the article also aims to make predictions by providing testable propositions and causal relationships (theory of explaining and predicting (Gregor, 2006)). From a literature perspective, this study intends to bridge the research on IT outsourcing and AIS, extending the research strands established for instance by Langfield-Smith and Smith (2003) and Weimer and Seuring (2009). 


\section{Conclusion and further research}

This article focuses on a cross-case study of outsourcing relationships of 7 business entities at a leading financial service provider with multiple external IT ADM suppliers and corresponding monitoring approaches. Relevant IT ADM monitoring dimensions are derived, and based on inter-rater reliability, a minimum set of IT ADM KPIs is suggested. This research aims to extend the research strands combining IT outsourcing with AIS research and proposes a model of effective monitoring IT ADM suppliers in multisourced environments.

The research contributes to the literature in several ways. First, the study contributes to the understanding of how large corporations monitor IT ADM suppliers by describing a real-life monitoring approach and its constituents. This approach encompasses respective multisourcing relationships between 7 business entities and multiple external IT ADM suppliers, mutually agreed KPIs between client organizations and suppliers, the formats and frequencies of reporting, the roles involved on the client organizations' side and suppliers' side, as well as an extensive list of KPIs applied to monitor IT ADM suppliers. The research reveals that besides the existence of standard IT frameworks such as COBIT and ITIL, practitioners have difficulty identifying relevant KPIs in the absence of a consistent, easy-to-implement KPI set. Further, the case study indicates the need to separate the monitoring of IT ADM suppliers and infrastructure suppliers because ADM is people-driven and mainly follows a project mode. Moreover, the interviewees argue that the aggregation of KPIs - vertical integration of KPIs within a business group - causes KPIs to become increasingly meaningless. Therefore, the interviewees sought to implement operational monitoring activities (such as IT ADM KPIs) exclusively on a local-business-entity level. Second, the research derives relevant monitoring dimensions based on cross-case analysis. Following the principles of BSC concepts, we propose the following dimensions with which to pursue effective monitoring IT ADM suppliers: time, quality, efficiency, monetary, customer and people. While typical (IT) BSC concepts are limited to internal (IT) departments, we extend these approaches toward outsourcing relationships with multiple external suppliers. Third, based on inter-rater reliability, we derive a minimum set of IT ADM KPIs that encompasses 19 KPIs to monitor IT ADM suppliers along the 2 ADM sub-functions, AD and AM. By doing so, we follow the principles of BSC concepts to limit the number of KPIs, while at the same time, we address the claim of practitioners for a recommendation of essential IT ADM KPIs. Accordingly, the KPIs are allocated to the monitoring dimensions suggested earlier. This method extends the standard IT frameworks by specifying KPIs for monitoring IT ADM suppliers. Finally, this research contributes to the understanding of why specific KPIs are employed by identifying the monitoring objectives and proposing a model of effective monitoring IT ADM suppliers in multisourced environments. In addition to its theoretical contribution, this research study is also expected to be useful for corporations facing similar challenges to organization ALPHA. The monitoring dimensions and the distinct KPIs are ready to implement and would provide any organization with a set of best-practice KPIs to monitor IT ADM suppliers. Additionally, by describing a real-life example of how and why a leading financial service provider monitors IT ADM suppliers, helpful advice is presented to practitioners.

However, the limitations of this research study must be acknowledged. First, the authors describe and analyze 7 case studies, but all of the studies are based on organization ALPHA. Nevertheless, organization ALPHA, one of the world's leading financial service providers, is characterized by a complex multisourcing approach and a decentralized organizational set-up in the context of a business group structure. Therefore, the units of analysis - the 7 business entities - are legally separate and obtain a high level of sourcing autonomy. Moreover, the selected business entities cover different regions of the world (Europe, America and Asia) that focus on diverse lines of business (insurance and banking). Second, the content evaluation panel is comprised of 9 subject matter experts. This number might seem minor; however, the composition of the panel does mitigate this limitation. The experts were selected based on their special knowledge of monitoring IT ADM suppliers in a multisourcing context and have on average 11 years of relevant experience. We invited representatives of 2 of the worldwide leading ADM outsourcing providers, one leading India-based ADM outsourcing provider and a leading consulting firm specializing in IT performance management. Experts from organization ALPHA's group center, which is responsible for sourcing and controlling, were also selected. Additionally, we followed the suggestion of Lawshe (1975, p.568) by applying the 5-percent rule and limiting the final set of KPIs to the essential ones. Third, our derived model is limited to the monitoring of IT ADM suppliers, and therefore, focuses on one specific IS function. However, this limitation is supported by the different characteristics of IS functions and the practical 
relevance of the research. To extend this research strand and to generalize or extend the model further, the authors suggest expanding the methodology of this research study to other IS functions described by Grover et al. (1996), especially infrastructure operations, because the interviewees emphasized the fact that monitoring differs between ADM suppliers and infrastructure suppliers. Researchers might investigate how infrastructure service suppliers are monitored and which KPIs are applied. Further, one might adapt the model and validate its applicability to IS functions other than IT ADM.

\section{Acknowledgments}

An earlier version of this article has been presented and discussed in the accounting information systems and enterprise systems track at the 6th Mediterranean Conference on Information Systems. We would like to thank the 4 anonymous referees and the editor for their excellent reviews and suggestions that significantly improved this article. Further, we would like to thank the organization ALPHA and the participants of the content evaluation panel.

\section{Appendix 1. Description of KPIs and CVR values (KPIs are sorted alphabetically)}

\begin{tabular}{|c|c|c|}
\hline KPI & Description & $\mathrm{CVR}^{\mathrm{c}}$ \\
\hline Attrition rate & Rolling year attrition rate & 0.99 \\
\hline Availability of application & Deviation of availability from appointed availability & 0.99 \\
\hline Budget compliance ratio & Deviation from appointed budget & 0.99 \\
\hline Change request rejection ratio & Number of changes rejected in terms of total change requests & -0.33 \\
\hline $\begin{array}{l}\text { Change requests after handover } \\
\text { to production }\end{array}$ & $\begin{array}{l}\text { Number of change requests within a defined time period after } \\
\text { handover to production }\end{array}$ & 0.33 \\
\hline CMMI compliance & Compliance with defined maturity level in CMMI & -0.33 \\
\hline Competence index & Average number of training days & -0.56 \\
\hline Cost of quality & Effort taken for reviews and testing & 0.11 \\
\hline Cost per function point & Average cost per function point & 0.56 \\
\hline Cost performance index & Efficient utilization of resources & -0.33 \\
\hline Defect density & Number of defects per development effort & 0.78 \\
\hline Defect distribution & Number of defects by development phase & 0.78 \\
\hline Defect removal index & Defects found prior to specific development phase & 0.78 \\
\hline Defects per function point & Average number of defects per function point & 0.56 \\
\hline Defects per severity level & Total number of defects per severity level & 0.33 \\
\hline First-time incident resolution rate & $\begin{array}{l}\text { Number of incidents solved first time (first contact) in terms of } \\
\text { the total number of incidents }\end{array}$ & 0.78 \\
\hline Frequency of releases & Time period in days between releases & -0.33 \\
\hline Function points per developer & Average number of function points per developer & 0.56 \\
\hline Function points per person day & Average function points per person day & 0.78 \\
\hline Functional compliance ratio & Project delivered within defined scope & 0.99 \\
\hline Incident backlog index & $\begin{array}{l}\text { Number of incidents closed in terms of opening balance of incidents } \\
\text { plus opened incidents }\end{array}$ & 0.78 \\
\hline Incident resolution time & Incident resolution time within SLA & 0.99 \\
\hline Incident response time & Incident response time within SLA & 0.99 \\
\hline Incidents per application & Average number of incidents per application & -0.11 \\
\hline Incidents per problem ratio & Number of incidents linked to a problem & 0.78 \\
\hline Incidents per severity level & Total number of incidents per severity level & 0.99 \\
\hline Lessons learned & Number of significant lessons learned per project & -0.56 \\
\hline Number of emergency change requests & Number of emergency change requests in terms of total change requests & -0.56 \\
\hline Problem backlog index & $\begin{array}{l}\text { Number of problems closed in terms of opening balance of problems } \\
\text { plus new problems }\end{array}$ & 0.78 \\
\hline Problem resolution time & Average time to resolve a problem & 0.99 \\
\hline Problems per application & Number of problems related to specific applications & 0.11 \\
\hline Problems per severity level & Total number of problems per severity level & 0.99 \\
\hline Project staffing & Planned project resources delivered on time & 0.11 \\
\hline Rate at which changes introduce problems & Percentage of changes introducing a problem & -0.33 \\
\hline Rate of change-related incidents & Percentage of incidents associated with a change & -0.56 \\
\hline Rate of unauthorized change requests & Number of unauthorized change requests in terms of total change requests & -0.78 \\
\hline Recurring incidents & Number of recurring incidents in terms of the total number of incidents & 0.78 \\
\hline
\end{tabular}


Appendix 1 (continued)

\begin{tabular}{lll}
\hline KPI & Description & \\
\hline Recurring problems & Number of recurring problems & \\
Rerouted incidents & Number of rerouted incidents in terms of the total number of incidents & 0.11 \\
Retention of key supplier staff & Retention of specifically defined supplier staff & 0.33 \\
Risk status & Status of projects according to defined risk measures \\
Satisfaction index & Customer satisfaction according to pre-defined questions \\
Schedule performance index & Efficient utilization of time & 0.11 \\
Staffing level (location) & Number of resources onshore vs. offshore & -0.33 \\
Staffing level (role) & Distribution of defined roles in AD/AM & -0.33 \\
Time compliance of releases & Deviation from planned release date & -0.33 \\
Time compliance ratio & Deviation from project milestones & -0.56 \\
\hline
\end{tabular}

c The CVR is negative when fewer than half of the experts evaluate the KPI as essential (Lawshe, 1975, p.567).

\section{References}

Albrecht AJ. Measuring application development productivity. Proceedings of the Joint SHARE/GUIDE/IBM Application Development Symposium. Monterey, (CA); 1979. p. 83-92.

Bapna R, Barua A, Mani D, Mehra A. Cooperation, coordination, and governance in multisourcing: an agenda for analytical and empirical research. Inf Syst Res 2010;21:785-95.

Beasley M, Bradford M, Dehning B. The value impact of strategic intent on firms engaged in information systems outsourcing. Int J Account Inf Syst 2009;10:79-96.

Benbasat I, Goldstein DK, Mead M. The case research strategy in studies of information systems. MIS Q 1987;11:369-86.

Beulen E, Fenema PV, Currie W. From application outsourcing to infrastructure management: extending the offshore outsourcing service portfolio. Eur Manag J 2005;23:133-44.

Blaskovich J, Mintchik N. Information technology outsourcing: a taxonomy of prior studies and directions for future research. J Inf Syst 2011;25:1-36.

Boehm BW. Software engineering economics. Upper Saddle River (NJ): Prentice-Hall; 1981.

Busi M, McIvor R. Setting the outsourcing research agenda: the top-10 most urgent outsourcing areas. Strateg Outsourcing 2008;1: 185-97.

Caglio A, Ditillo A. A review and discussion of management control in inter-firm relationships: achievements and future directions. Account Org Soc 2008;33:865-98.

Clark TD, Zmud RW, McCray GE. The outsourcing of information services: transforming the nature of business in the information industry. J Inf Technol 1995;10:221-37.

Cohen LR, Young A. Multisourcing: moving beyond outsourcing to achieve growth and agility. Bosten (MA): Harvard Business School Press; 2006.

Corbin JM, Strauss AL. Grounded theory research: procedures, canons and evaluative criteria. Qual Sociol 1990;13:3-21.

Cross J. IT outsourcing: British Petroleum's competitive approach. Harv Bus Rev 1995;73:94-102.

Das TK, Teng BS. Trust, control, and risk in strategic alliances: an integrated framework. Organ Stud 2001;22:251-83.

Davis KJ. IT outsourcing relationships: an exploratory study of interorganizational control mechanism. Boston (MA): Harvard University; 1996.

Davis E. The 10 steps to multisourcing successfully. Cambridge (MA): Forrester Research, Inc.; 2010 [Available: http://www.forrester.com/ The+10+Steps+To+Multisourcing + Successfully/fulltext/-/E-RES55990. Accessed: 23.03.2012].

Denzin N. The research act: a theoretical introduction to sociological methods. Piscataway (NJ): Transaction Publishers; 2009.

Dibbern J. The sourcing of application software services: empirical evidence of cultural, industry and functional differences. Heidelberg: Physica-Verlag; 2004.

Dibbern J, Goles T, Hirschheim R, Jayatilaka B. Information systems outsourcing: a survey and analysis of the literature. DATA BASE Adv Inf Syst 2004;35:6-102.

Eisenhardt KM. Control: organizational and economic approaches. Manag Sci 1985;31:134-49.

Eisenhardt KM. Building theories from case study research. Acad Manage Rev 1989;14:532-50.

Faraj S, Sproull L. Coordinating expertise in software development teams. Manag Sci 2000;46:1554-68.

Glaser BG, Strauss AL. The discovery of grounded theory: strategies for qualitative research. Chicago (IL): Aldine Publishing Company; 1967.

Goo J, Kishore R, Rao HR, Nam K. The role of service level agreement in relational management of information technology outsourcing: an empirical study. MIS Q 2009;33:119-45.

Gottschalk P, Solli-Sæther H. Critical success factors from IT outsourcing theories: an empirical study. Ind Manag Data Syst 2005;105: 685-702.

Gregor S. The nature of theory in information systems. MIS Q 2006;30:611-42.

Grover V, Cheon MJ, Teng JTC. The effect of service quality and partnership on the outsourcing of information systems functions. J Manag Inf Syst 1996;12:89-116.

Hodgkinson SL. The role of the corporate IT function in the federal IT organization. In: Earl MJ, editor. Information management: the organization dimension. Oxford: Oxford University Press; 1996. p. 247-69.

Huber B. Agile multi-sourcing: a critical business trend, concepts and background. Houston (TX): Technology Partners International, Inc.; 2008 [Available: http://www.tpi.net/pdf/papers/AgileMulti-Sourcing.pdf. Accessed: 03.02.2011].

ITGI. COBIT 4.1. Rolling Meadows (IL): IT Governance Institute; 2007.

ITGI. Enterprise value: governance of IT investments, the Val IT Framework 2.0. Rolling Meadows (IL): IT Governance Institute; 2008.

Janischowsky B, Schonenbach R. Getting multisourcing right! CEO Today 2009;2:78-80.

Kaplan RS, Norton DP. The balanced scorecard. Boston (MA): Harvard Business School Press; 1996. 
Keating PJ. A framework for classifying and evaluating the theoretical contributions of case research in management accounting. J Manag Account Res 1995;7:66-86.

Kirsch LJ, Sambamurthy V, Ko DG, Purvis RL. Controlling information systems development projects: the view from the client. Manag Sci 2002;48:484-98.

Klepper R. The management of partnering development in I/S outsourcing. J Inf Technol 1995;10:249-58.

Kobelsky KW, Robinson MA. The impact of outsourcing on information technology spending. Int J Account Inf Syst 2010;11:105-19.

Lacity MC, Willcocks LP. An empirical investigation of information technology sourcing practices: lessons from experience. MIS Q 1998;22:363-408.

Langfield-Smith K, Smith D. Management control systems and trust in outsourcing relationships. Manag Account Res 2003;14: 281-307.

Lawshe CH. A quantitative approach to content validity. Pers Psychol 1975;28:563-75.

Levina N, Su N. Global multisourcing strategy: the emergence of a supplier portfolio in services offshoring. Decis Sci 2008;39:541-70.

Looso S, Goeken M, Johannsen W. Comparison and integration of IT governance frameworks to support IT management. In: Praeg CP, Spath D, editors. Quality management for IT services - perspectives on business and process performance. Hershey (PA): Business Science Reference; 2011. p. 90-107.

Mayo M, Lang T, Aitchison D. The TPI index: an informed view of the state of the global commercial outsourcing market - fourth quarter and full-year of 2009. Houston (TX): Technology Partners International, Inc.; 2010 [Available: http://www.tpi.net/web/ research-insights/tpi-index/. Accessed 04.02.2011].

McFarlan FW, Nolan RL. How to manage an IT outsourcing alliance. Sloan Manage Rev 1995;36:9-23.

McMillan J. Managing suppliers: incentive systems in Japanese and U.S. industry. Calif Manage Rev 1990;32:38-55.

Nicolaou AI. Editorial: a dialectic on methodologies in AIS research. Int J Account Inf Syst 2011;12:81-3.

OGC. The official introduction to the ITIL service lifecycle. Norwich: The Stationery Office; 2007.

Oshri I, Kotlarsky J, Rottman JW, Willcocks LP. Global sourcing: recent trends and issues. Inf Technol People 2009;22:192-200.

Oshri I, Kotlarsky J, Willcocks LP. The handbook of global outsourcing and offshoring. 2nd ed. Basingstoke: Palgrave Macmillan; 2011.

Ouchi WG, Maguire MA. Organizational control: two functions. Adm Sci Q 1975;20:559-69.

Palvia P, Pinjani P, Sibley EH. A profile of information systems research published in Information \& Management. Inf Manage 2007;44:1-11.

Patton MQ. Qualitative research and evaluation methods. 3rd ed. Thousand Oaks (CA): Sage Publications; 2002.

Poppo L, Zenger T. Do formal contracts and relational governance function as substitutes or complements? Strateg Manag J 2002;23: 707-25.

Porter ME. Competitive advantage. New York (NY): Free Press; 1985.

Rajkumar TM, Mani RVS. Offshore software development: the view from Indian suppliers. Inf Syst Manage 2001;18:63-73.

Richardson J. Parallel sourcing and supplier performance in the Japanese automobile industry. Strateg Manag J 1993;14:339-50.

SEI. CMMI for Development, Version 1.3. Pittsburgh (PA): Software Engineering Institute, Carnegie Mellon University; 2010.

Smith JA, Morris J, Ezzamel M. Organisational change, outsourcing and the impact on management accounting. Br Account Rev 2005;37:415-41.

Su N, Levina N. Global multisourcing strategy: integrating learning from manufacturing into IT service outsourcing. IEEE Trans Eng Manage 2011;58:717-29.

Tapper D. Worldwide and U.S. IS outsourcing services 2009-2013 forecast update: November 2009. Framingham (MA): International Data Corporation (IDC); 2009.

Taylor S, Cannon D, Wheeldon D. ITIL: service operation. Norwich: TSO Publications; 2007a.

Taylor S, Case G, Spalding G. ITIL: continual service improvement. Norwich: TSO Publications; 2007b.

Taylor S, Iqbal M, Nieves M. ITIL: service strategy. Norwich: TSO Publications; 2007c.

Taylor S, Lacy S, Macfarlane I. ITIL: service transition. Norwich: TSO Publications; 2007d.

Taylor S, Lloyd V, Rudd C. ITIL: service design. Norwich: TSO Publications; 2007e.

Van Grembergen W, Saull R, De Haes S. Linking the IT balanced scorecard to the business objectives at a major Canadian financial group. In: Van Grembergen W, editor. Strategies for information technology governance. Hershey (PA): Idea Group; 2004. p. 129-51.

Weimer G, Seuring S. Performance measurement in business process outsourcing decisions: insights from four case studies. Strateg Outsourcing 2009;2:275-92.

Willcocks LP, Choi CJ. Co-operative partnership and "total" IT outsourcing: from contractual obligation to strategic alliance? Eur Manag J 1995;13:67-78.

Willcocks LP, Lacity MC. IT outsourcing in insurance services: risk, creative contracting and business advantage. Inf Syst J 1999;9:163-80.

Yin RK. Case study research: design and methods. London: Sage; 2003.

Zorn T, Campbell N. Improving the writing of literature reviews through a literature integration exercise. Bus Commun Q 2006;69: $172-83$. 